\section{The Allegation of Abuse as a Modality of Adolescent Onset}

\author{
Emmanuel de Becker* and Sophie Dechêne \\ Child and Adolescent Psychiatry Department, Catholic University of Louvain,
} Brussels, Belgium

\begin{abstract}
The narcissistic question is determining in the adolescence period, whatever their gender, their family of origin, the cultural context, the condition of the subject. This sensitive question can know diversions susceptible to compromise, sometimes severely, their psychological development and perhaps their final psychological construction or even mental state. An assertion of ill-treatment, and certainly when it concerns the family links, places the young person in the center of extreme stakes in which the mechanisms of identification and projection engender diverse disorders arousing guilt and anxiety. This assertion, included as a modality of expression of a suffering, asks for an attentive and friendly listening when it is not an act of protection. In the light of a case report, we suggest questioning the ins and outs of a situation as well as its multiple meanings before continuing our reflections on the main axes of care.
\end{abstract}

Keywords: Adolescence; Adolescent process; Allegation; Child abuse; Individuation

\section{Introduction}

The concept of narcissism, that is to say, literally the love brought of one's own image, represents a key concept in understanding the psycho-emotional development of the individual. Abuse in any form undermines narcissism, particularly in today's societies which are so sensitive to any aggressive movement towards the subject's integrity. As many authors, such as Discour, Le Naour and Maïdi point out, narcissism and its many facets is one of many sensitive issues in adolescence [1-3]. While narcissism can be a vivifying source, it can equally destroy self-image and personal self-esteem in the midst of metamorphosis, leaving the young subject in pain and distress, helpless in the face of instinctual aggressive forces [4]. Kestemberg states that

*Corresponding author: Emmanuel de Becker, Child and Adolescent Psychiatry Department, Catholic University of Louvain, Brussels, Belgium, Tel: +3227642090; E-mail: emmanuel.debecker@uclouvain.be

Citation: de Becker E, Dechêne S (2019) The Allegation of Abuse as a Modality of Adolescent Onset. J Psychiatry Depress Anxiety 5: 027.

Received: September 09, 2019; Accepted: September 23, 2019; Published: September 30, 2019

Copyright: $\odot 2019$ de Becker $E$ and Dechêne S. This is an open-access article distributed under the terms of the Creative Commons Attribution License, which permits unrestricted use, distribution, and reproduction in any medium, provided the original author and source are credited.

\begin{abstract}
"the difficulties of adolescents' relationships with others, especially adults, that is to say the need of adolescents to brutally reject the characters and imagos of parents, induce in these subjects deep difficulties in their relationships with themselves, in expressing themselves, and, explicitly or implicitly, in a more or less intense anxiety about their own self " [5].The dialectic of narcissistic and object satisfaction during adolescence, under the impulsion of genital maturation, leads to the resurgence of unconscious conflicts in primitive object relations, the supports of the subject's narcissistic foundations [6]. One way of relieving these relational tensions consists in an enunciation of the suffering outside the family's field, sometimes putting family connections at risk. In the light of a case report this article elaborates a reflection on the allegation of maltreatment as a factor in weakening parental function as a modality of the commencement and duration of adolescence.
\end{abstract}

\section{Theoretical Considerations}

As mentioned above, abuse has a particularly negative impact on adolescents' narcissism. Freud showed that the Ego development consists of moving away from primary narcissism; this distance is made possible by the displacement of the libido on an Ideal of the Ego, any satisfaction being realised by the fulfilment of this Ideal [7]. In this movement, the young person is expected to be able to negotiate a new "narcissistic contract" at the centre of essentially unconscious structuring alliances. Following Kaës, we develop this "narcissistic contract" into several interdependent levels, each of which involves issues that go far beyond the questions of the present study [8].

For Jeammet, one of the major problems the adolescent encounters is the consequence of his sexual genital maturation, because the latter leads to the possibility of an enactment of his incestuous and murderous fantasies [9]. The use of external objects from childhood to ensure one's own balance is harmed by the occurrence of genital sexuality and the resulting change in the state of the adolescent's body. The fantasy now feasible, resolution modes are created by the teenager to allow the continuation of meeting in other ways. Parental positioning is therefore essential. Parents are expected to demonstrate both firmness and flexibility. They represent indemnificatory bases on which the young person can orient himself while developing his individuality. An oscillation (between distance and closeness) characterises the relationship between the young and the adult, depending, among other things, on the ability of the latter to manage the situation with kindness [10]. If this foundation is too lax or too rigid, the teenager will not be able to emerge serenely from adolescence and, instead, will spend these formative years in a harmful state of anxiety. In certain circumstances, the parent will jeopardise the adolescent's narcissistic contract, the adolescent will then attempt to escape from this situation, alleging possible abuse, whether physical or psychological. Another crucial aspect of the allegation of abuse, certainly when it is of a physical nature, concerns the body, that vulnerable envelope, and the reflection of being in metamorphosis. In the case of physical aggression, the young person can potentially be severely affected. The body represents another essential dimension for it is expected to be appropriated by the adolescent in a manner related to his own history. 
Winnicott speaks of "personalisation" as a phenomenon of the body being inhabited by the psyche [11]. A period of necessary deconstruction allows, as Cahn and Gutton point out, a "subjectivation" to understand such a "violence of life" [4,12]. Although, in essence, the body belongs to the adolescent, and is thus an element of his intimate being and intimacy, it also belongs to an objective and objectified external reality. Thus it partly escapes the subject's control, constituting a kind of unpredictable host for the Self, while still being a part of the Self. The teenager goes through a deconstruction of the body in which his parents, mainly his mother, have invested in order to be reborn in his own body. This transformation is rarely affected without avatars and it is not uncommon to note various bodily attacks such as scarification and other mutilator practices [13]. Following Le Breton, we hear how pain is an integral part of the act of the "depersonalisation of the body", the physical suffering authenticating the taking of possession of this carnal envelope [14-16]. However, pain transcends the body and is found in relational issues. Let us note that an "individual in the making" must, in a certain way, be cut off from the child's body to be open to the fulfilment of a personal sexual desire. The adolescent body is expected to be recognised as both desiring and an object of desire, distinct from maternal care and incestuous impulses.

\section{Discussion}

At first glance, the adolescent's speech needs to be understood as an expression of a life instinct directed at the adult. However, families and professionals regularly question the credibility and authenticity of this speech. The adolescent himself can sometimes become entangled in lies, story-telling, or be confused, without suffering from any mental illness.

For centuries, the minor's speech has hardly been taken into consideration. It was not until the establishment of the International Convention on the Rights of the Child in 1989 that children were recognised as a subject of and subject to the law. To wonder about false allegations made by a child invites us to first consider the status of his speech. Today, the child is assured of his rights, while sometimes enjoying an excessively-elevated or inappropriate position in family and societal dynamics $[17,18]$. The disproportionate attention given by the adult, if not limitless, to his desires inevitably leads to an overflowing of acting-out, concomitantly with an increase in anxiety [19]. His words are also increasingly taken into account, especially when the words spoken question the adequacy of adults towards him [20-22]. Moreover, it must be remembered that humans, in general, speak not to tell the truth but to build and enter into relationships. On the basis of this evidence, we must always pay attention to aspects of credibility, when the allegation calls into question the adequacy in the bonds as important as those that concern the primary attachment. We have developed two distinct qualifications of the child's enunciation, namely authenticity and reliability [23]. It should be noted that the first dimension relates to emotional experience, to what the individual feels about himself and about others, while the second takes into account his knowledge about the world around him. Reliability refers to aspects of intelligence, addressing the multiple information from the world in general, stemming from others but also from one. We must obviously take into account the developmental age of the individual. Thus, the younger the subject is, the more cautiously the professional must intervene by giving him the opportunity to fully express information that he sometimes condenses in order to be understood. Both authenticity and reliability, qualities inherent in speech, can, at times, be faulted for various reasons. Without being exhaustive, let's take a look at some situations in which questions and doubts seize the intervener in the face of a child or a teenager who alleges abuse of a third party.

Note that many professionals believe that truth comes out of children' mouth and therefore their words cannot suffer any questioning. This position is likely to become more rigid in the case of allegations of abuse because these same professionals cannot conceive the possibility of falsification on the part of the young person. This being emphasised, can the young person lie? Remember that lies can be defined as an enunciation that intentionally falsifies what it is supposed to describe or relate. Thus, the person who lies purposely deceives the interlocutor.

One can also speak of a lie when one deliberately omits information crucial to others. This last aspect obviously requires some nuance given the need to have reached a developmental age sufficient to grasp all the consequences of an allegation, whether truthful or falsified. Be that as it may, from a very young age, the human is capable of lying and will never avoid using it for several reasons. Various issues are encountered in explaining the lie regardless of the individual's age. He is likely to express false information because he is knowingly lying. Those described as "intentional" lies appear more frequently when the subject grows up and reaches adolescence. On another level, we can evoke the phenomenon of dramatized meaning when the young person has the correct intuition about the behaviour of an adult towards him. In a way, he senses what has not happened yet [24]. This dramatization of the intention, and not that of the act, which has not (yet) taken place is equivalent in some way to a defensive mechanism that can be described as intuitive. We propose to schematically regroup various motivations, underlining that these partially overlap and that any lie can correspond to several intentions. This article will only deal with the use of lies among young people with relatively stable mental health and cognitive development. It is essential to take into account the context in which the teenager who uses falsehood develops, given the constant interactions between the socio-emotional environment and the act of lying.

It should also be noted that certain families use lies on a regular basis either within their private life or in their interactions with the outside world; here, the young person reproduces what he has learned in his family. Let's pinpoint some meanings and intentions of the lie as stated by the teenager:

\section{To exist}

Sometimes the individual is attempting to exist in a certain way for himself and in the eyes of others, the lie allowing him to avoid the threat of being forgotten or not being acknowledged. By lying, the adolescent wants to occupy a place and/or a function in his reference group or his community. If we can understand the lie as a weapon on the side of the living, it can be a defensive mechanism against a death drive, possibly activated by a trauma or a family rupture such as an acrimonious parental separation $[25,26]$.

\section{To promote oneself}

Another perspective concerns the primary need for some individuals to value themselves in front of others and to strengthen their narcissism. An imaginative, fertile mind, fed by new technologies and multiple screens, levels the demarcation between fantasy and reality. 
These young people do not belong to the category of those suffering from pervasive developmental disorders. Lying can also be understood as a defensive mechanism for young people who are lacking an adequate caregiver, are neglected, or are not valued by those around them. Further, it can lead to confabulations which reflect, if they are frequent, an unhealthy mental state.

\section{To master}

Following the preceding point, by lying, the young person may want to have control over his environment and to feel omnipotence. This act can be conscious or unconscious. As the creator of a certain reality, he enjoys mastering his environment as well as observing the disorder induced in it [27]. But he may experience the risk of any self-containment that generates radical isolation, as he cuts himself off from sincere and genuine relationships.

\section{To obtain}

The young person is likely to consciously use lies to obtain material advantages or to avoid inconveniences, for example due to relational issues. Confronted with frustration, every human perceives the discontinuity between his own desire and the limits of his environment. By lying, he attempts to obtain the object of his desire, to circumvent the obstacles, or to achieve one or another of his interests. The younger the individual, the more the effects of frustration and dissatisfaction are diminished by material gratification. Corollary to this dimension, the teenager can lie to establish his power. It is obvious that situations of parental separation with alternating living arrangements favour the use of lies.

\section{To protect (oneself)}

Faced with a violent or a threatening adult, or one perceived as such, the young person soon understands the strength of lying; it is about protecting oneself or someone else. Thus, in the context of family violence or abuse, lies play a defensive role and, here again, participate in the dramatic aspects of conflicts of loyalty in acrimonious separations. Contexts of domestic abuse are cases in which the professional finds the false allegation to be a defensive modality for the protection of oneself, any potential siblings, or one of the parents. The price to pay is far from negligible. Indeed, the adolescent can trivialise this way of expressing himself and finally generalise and extrapolate it well beyond the conflictual family context. The field of socialisation is then concerned. The young person rushes into lies and loses sight of the modalities for escaping this process. Anguish, shame, and guilt lock him in, compelling him to continue on this path, isolating him a little more with each new lie. The expression of truth then becomes practically impossible [28].

\section{To emerge}

Finally, the adolescent uses falsehood to hatch in his process of metamorphosis, as he is forced to go through antagonistic re-shaping. For example, there is a paradox in adolescence, specifically that which governs the relationship between narcissism and object relations, between self-investment and the investment of the other. Indeed, the adolescent must change while remaining the same from an identity point of view. He is led to maintain a certain continuity of existence despite the discontinuity introduced by pubertal modifications. We also observe hit her to un-encountered bodily behaviours on the side of inhibition or withdrawal, or, conversely, on the side of potentially very loud acting out; these are attempts to express internal conflicts in which language can go beyond thought or no longer serve it. In some oppressive and rigid family contexts, there is hardly any possibility of individuation. Unflinching loyalty is expected by adults who are ready to sacrifice themselves for their offspring. In this case we are far from seriously inadequate transactional patterns with visible maltreatment, or with abuse known to third parties. The inadequacy is much more subtle and nuanced to the point where clinicians are blinded to it.

\section{Management}

\section{State of mind}

The reception of speech by a professional is mainly supported by the intrinsic qualities of the adult alongside his working paradigm. While psychodynamic epistemologies have highlighted the importance of imagination, fantasy, and drive in the young, sometimes leading to a certain perplexity about the credibility of his speech, other attitudes are held, based on an unconditional understanding of the reality evoked by them as truth. Extreme positions, on the one hand scepticism and on the other an unfailing belief, are found on the part of the professionals, each as damaging as the other to this subject.

We must note that the allegation of abuse expressed by a young person is never trivial and must always be taken seriously and cautiously. Truth or lie? In some cases, some doubt will remain, generating at least some sense of discomfort in the social and family environment. Support will be all the more necessary as the pressure on the adolescent will not be easily removed, given the significant stakes raised and maintained by the uncertainty and/or convictions of each party. The young person, without having necessarily anticipated it, finds himself at the heart of anxiety-provoking attentions and expectations. One of the clinician's roles is to support him by meeting him in an attempt to approach the materiality of the facts contained in the allegation, not in the spirit of a search for evidence but with a therapeutic intention [29]. Indeed, we believe that the enunciation and reality lived by the youth must be taken into consideration. The professional must enable the youth to speak without embarrassment of the aggressive events which he claims to have undergone, respecting his pace, his silences, his hesitations, and helping him to participate in the process of care. Taking into account the youth's anxiety, it is sometimes useful to precede his expression in order to, to an extent, facilitate it by not remaining in a listening attitude of silent availability, as, while certainly benevolent, the youth may find this approach remote.

It should also be remembered that the younger the individual, the stronger his suggestibility, and the more the characteristics of conformity and submission are found. He tries to adapt to what his imagination tells him about the adult's expectations. Sensitive to the fact that an adult is interested in his well-being, he can answer the most surprising questions; amplify certain details, through the sole belief of being obliging. Many young teens work on a story memory that consists of constructing a story through associations of diverse and scattered elements. In addition to cognitive characteristics related to the developmental age, it is necessary to take into account the affective elements. His level of anxiety, his feeling of guilt, his defensive mechanisms as well as his possible identification processes, are all aspects to approach during the first interviews. To be relevant, they 
must be contextualised and integrated into a singular and child-specific history. Individuals behave differently depending on their environment and the pressures of their environment, internal tensions leading them, for example, to opt for mutism, retraction, maintenance of the allegation, or identification with the ideology of their abuser, something which can go as far as the development of Stockholm syndrome.

\section{Methodology}

Contrary to what some people think or hope, we do not have foolproof techniques that can remove any doubt about the content of an allegation. No more than for adults, one cannot completely dismiss a certain amount of uncertainty in the adolescent's speech [28]. As soon as the words of all young children emerge, the interlocutor is confronted with the non-mastery of a truth that belongs only to the subject that is stated. This being underlined, we can reduce the test of doubt by using, alongside classical speaking sessions, interview techniques and targeted tests on the teenager and those around him. It is also interesting to work on the assessment from the perspective of different clinicians from complementary disciplines [30]. Thus psychologist, social worker, and child and youth psychiatrist work together to cover several levels of investigation. The purpose is to listen, gather information, seek and make sense of acts and attitudes, and to evaluate possible traumatic impacts, while ensuring the mobilisation of individual and systemic resources. The analysis of the credibility of speech remains a delicate act. This is why, for several years, the evaluation of a child's speech has been carried out through rigorous techniques, using those which are least suggestive. For example, we have the Quebec statement validity analysis (SVA), developed by Yuille and Van Gijseghem [31,32].

There are corollary methods of conducting specific evaluative interviews, such as the National Institute of Child Health and Human Development (NICHD) method, built on open questions [33]. In addition, it is interesting to use complementary tests targeted at the young person himself, the parents, and the family. For example, the Child Behaviour Check List (CBCL) consists of a rating scale of psychopathological states, assessing mental health, emotional and behavioural disorders, and social skills of children from one to eighteen years of age. The Adult Adolescent Parenting Inventory (AAPI) is designed for the assessment of parenting, such as attitudes, beliefs, and parents' skills in relation to their child's education. The Minnesota Multiphasic Personality Inventory, Version 2 (MMPI 2) was developed to reliably and completely discern personality by highlighting possible psychological disorders. The Family System Test (FAST) was created to collect data on the perceptions of family relational structures of subjects over six years old. The Family Apperception Test (FAT) is a projective assessment based on the theory of the family system. Of course, the list of diagnostic tools that can contribute to the evaluation is long. Those we have mentioned are part of a research protocol conducted within our specialised team; they have demonstrated their relevance to the defined goal [34]. In addition, projective tests (such as CAT, TAT, Rorschach) offered both to the young person and to the parents reveal useful elements with regard to the psychological and relational functioning of the subject. One sore point is the problem of retraction. Indeed, in the wake of a false allegation, we find young people who retract, while we must simultaneously stress that nearly a third of reliable victims retract their speech in the process of crisis that follows the revelation. We refer the reader to authors such as Summit who have described this phenomenon [35]. In our experience, we have observed three categories of retractions in intra-familial abuse based on their moment of appearance in the process. Older adolescents, more anxious or more fragile, and subject to strong internal tensions, seem to retract after the revelation given to the first confidant. Others, often younger, retract during the assessment phase when external pressures are significant. Finally, there are late retractions when the youth has been placed with or returned to their family [36].

\section{Therapeutic Intention}

To arrive at a diagnosis of a misleading claim is in itself only a step in the care of the patient; it certainly marks progress but is in no way an end in itself. In the opposite case, the young person and those around him would be left subject to emotional turmoil, which would inevitably lead to maltreatment due to the narcissistic injuries caused. How can we conceive that parents would welcome back their child who has accused them of one of the greatest evils related to parenting? We advocate, at the very least, a "space-time", with a possible temporary separation of the protagonists and meetings at a sustained pace, in individual, couple and family formats [37]. Coming to a diagnosis of false allegations usually sees the family regard the adolescent as an individual suffering from psychiatric problems. If the attachment bonds are already insecure, the crisis triggered by the alleged abuse often only amplifies the existing breaks with the corollary rejection of the member by the family system, the child being perceived as a disloyal ward. The professionals are then expected, from the point of the enunciation of legitimate anger, to propose a re-development of the interactional patterns. It is interesting that each protagonist, first individually and then in a family interview, positions himself in his relationships with others and accesses the conscious and unconscious elements belonging to him and those of the family system who contributed during the emergence of the allegation. During meetings, we are particularly attentive to the phenomenon of deconstruction and its articulations in relation to the personal elements of the adolescent, as well as those of the social and family environment.

This deconstruction is sometimes made impossible if the young person perceives major risks to himself, to his family, or, indeed, if there is nothing to deconstruct. Attention is also focused on the places assigned by the surrounding individuals, mainly the parents, on the idealised places, or on places forbidden by the parents. This is the case when the adolescent is unable to live out his own existence and must abide by the expectations, explicit or implicit, of the parents. The adolescent transformation is to be understood as a process of deconstruction leading the young person to occupy a place independent of the parental verdict [38]. This deconstruction unfolds, among other things, in games. In recent years, the use of games has experienced an as of yet unparalleled deployment. Indeed, virtual worlds provide possibilities for realising experiences of identity transformations. These experiences allow the renegotiation of the narcissistic contract by a necessary play between the imperatives of the young person's personal development and the constraints, or even the possibly contradictory demands, of the family and institutions. One of the therapeutic aims is therefore to enable the adolescent to become a "cosignatory of the contract of his own life". Nuance is necessary when one evokes the notion of deconstruction. On the one hand, we encounter an object-based deconstruction aimed at deconstructing the object relations in order to transform them into the finality of leaving a new place for the individual and, on the other hand, a deconstruction of the narcissistic, anti-object type which causes the subject to 
turn on himself. In addition to this development, we can use targeted media transactional patterns operating within the family such as the Minuchin structural map, a mode of analysis of the family functioning in the present and in terms of transmission [39]. From the different types of attachment, we can approach the quality of the set base, analyse the borders with the outside world, the distribution of the roles, the management of conflicts, and the family structure. As a result, the therapeutic perspective aims to revitalise the injured family unit by supporting new adaptive capacities, by rewriting functional patterns that are conducive to the expected changes. It is also necessary to support the movement of connection between emotions and the rational development of events. The trauma experienced can indeed freeze, in some individuals, the ability to disconnect cognitive functioning and emotions [40]. To carry out these projects, it is useful and relevant to use split co-therapy. One clinician meets the young person while a second supports the parents in their own self- and more formal questioning, before carrying out, at the appropriate time, family interviews that facilitate listening as well as mutual understanding [41-43]

\section{Conclusion}

The emergence of the collective awareness of child abuse has generated legitimate indignation. It has also created an atmosphere of passion and even a "dictatorship of emotions" maintained by various sources [29]. In this climate, it is not easy to take proper stock of the place of lies and the fact that the child or adolescent may not necessarily be telling the truth. But what truth? In many cases, the claim must be heard and understood as an appeal for help, as an expression of suffering, even if the family circle cannot initially have access to or understand this aspect [44].We have noticed a form of "sacralisation" of the speech of minors, a tendency to interpret their words literally, that is to say to deprive ourselves and those involved of a real interpretation. The professional attitude should therefore consist in opening hypotheses, because nothing is more dangerous than an idea when one has only one. It is necessary to be able to consider various possibilities, even when faced with a young person whose word one feels uncomfortable to doubt or to not necessarily believe.

\section{References}

1. Discour V (2011) Changes in the body and psychic reworking in adolescence. Dynamic Books 50: 40-46.

2. Le Naour R (2008) The question of identity and narcissism in adolescence. Psychiat Info 84: 149-154.

3. Maïdi H (2014) Narcissism in adolescence. J Child Psychoanal 4: 123-140.

4. Gutton $\mathrm{Ph}$ (2003) The pubertary. PUF.

5. Kestemberg E (1999) Identity and identification in adolescents. Teen adolescence 8: 7-96

6. Gutton Ph (2006) Teenage unmasked. Adolescence 57: 573-591.

7. Freud S (2005) Introduction to narcissism volume XII. PUF.

8. Kaës R (2009) The unconscious alliances. Dunod, Paris.

9. Jeammet $\mathrm{Ph}$ (2003) The issues of identifications in adolescence. Child Adol Psychother, Bayard.

10. Lesourd S (2007) Teenage construction. Erès.

11. Winnicott DW (1962) Adolescence, deprivation and delinquency. Payot, Paris.
12. Cahn R (2000) Subjectivation. Dictionary of Psychopathology of the Child and Adolescent, PUF.

13. Le Goaziou V, Mucchielli L (2009) Violence of young people in question, Nîmes, Social Field.

14. Le Breton D (2007) Suffering. Adolescence and entry into life. Métailié, Paris.

15. Le Breton D (2015) Rhythms of virility in adolescence. Brussels.

16. Le Breton D (2016) Body and Adolensence. Bruxelles.

17. Halmos C (2006) Why love is not enough. Paris.

18. Marcelli D (2009) It is permissible to obey: obedience is not submission.

19. van Meerbeeck, Mikolajczak A (2003) The infamily or perversion of the link, Oxalis, De Boeck University.

20. Haesevoets YH (1997) The child victim of incest, Brussels.

21. Haesevoets YH (1999) Allegations of sexual abuse in children between doubt and absolute conviction, Psychiatric Evolution 64: 337-348.

22. Haesevoets YH (2000) The child in question, Brussels.

23. Hayez JY, de Becker E (2010) The word of the child in pain: welcome, evaluate and accompany. Dunod, Paris.

24. Haesevoets YH (2003) Plural View on Child Abuse. Brussels.

25. Braconnier A, Golse B (2008) Our babies, our teenagers.

26. Braconnier A (2015) Optimistic. Paris.

27. Hayez JY (2004) The sexuality of children. Paris.

28. Hayez JY, de Becker E (1999) The speech of the minor on the sexual abuse, False positives and non-credibility. Leuven Medical 118: 497-507.

29. de Becker E (2006) Allegation of Sexual Abuse: Between Lie and Truth ?. Neuropsych Childhood Adol 54: 240-247.

30. Hayez JY, de Becker E (1997) The child victim of sexual abuse and his family. Evaluation and treatment, PUF, Paris.

31. Yuille JC (1988) The child's interview in an investigative context and the systematic evaluation of his statement. Canadian J Psychol: 1-20.

32. Van Gijseghem H (1999) Us and abuse. From words to words about sexual abuse. Montreal, Canada, Le Méridien.

33. de Becker E (2017) The child victim of sexual abuse and his family: assessment and treatment. Twenty years later?. Medic Psycholog Ann: 415-421.

34. de Becker E, Maertens MA (2015) The future of the child victim of sexual abuse. Medic Psycholog Ann 173: 805-814.

35. Summit RC (1983) The child sexual abuse accommodation syndrome. Child Abuse Neglect 7: 177-193.

36. de Becker E, Verheyen C (2012) False allegations of sexual abuse in prepubertal children. Psychotherapies: 179-189.

37. Lernout $\mathrm{N}$ (2006) Use of the diagram of the organization of the human environment and more particularly the level of the atmosphere in therapy. Fam Ther 27: 293-220.

38. Matot JP (2012) The adolescent issue, PUF.

39. Minuchin S (1998) Families in therapy. Reissue Eres, Ramonville-Ste-Agne.

40. Dessoy E (1997) Rites of passage and psychotherapies: how to remobilize suspended time?. Fam Ther 18: 49-69. 
Citation: de Becker E, Dechêne S (2019) The Allegation of Abuse as a Modality of Adolescent Onset. J Psychiatry Depress Anxiety 5: 027.

- Page 6 of 7 •

41. Blos P (2012) The Second Individuation Process. Psychoanal Study Child 22: $162-186$.

42. Laufer M (1964) The ideal of the self and the pseudo-ideal of the ego. French J Psychoanal 44: 591-615.
43. Laufer M (1989) Adolescence and developmental failure. PUF, Paris.

44. Goldbeter-Merinfeld E (2005) Attachment Theory and Systemic Approach. Fam Ther Crit Books Network Pract 35: 13-28. 


\section{II}

Journal of Anesthesia \& Clinical Care

Journal of Addiction \& Addictive Disorders

Advances in Microbiology Research

Advances in Industrial Biotechnology

Journal of Agronomy \& Agricultural Science

Journal of AIDS Clinical Research \& STDs

Journal of Alcoholism, Drug Abuse \& Substance Dependence

Journal of Allergy Disorders \& Therapy

Journal of Alternative, Complementary \& Integrative Medicine

Journal of Alzheimer's \& Neurodegenerative Diseases

Journal of Angiology \& Vascular Surgery

Journal of Animal Research \& Veterinary Science

Archives of Zoological Studies

Archives of Urology

Journal of Atmospheric \& Earth-Sciences

Journal of Aquaculture \& Fisheries

Journal of Biotech Research \& Biochemistry

Journal of Brain \& Neuroscience Research

Journal of Cancer Biology \& Treatment

Journal of Cardiology: Study \& Research

Journal of Cell Biology \& Cell Metabolism

Journal of Clinical Dermatology \& Therapy

Journal of Clinical Immunology \& Immunotherapy

Journal of Clinical Studies \& Medical Case Reports

Journal of Community Medicine \& Public Health Care

Current Trends: Medical \& Biological Engineering

Journal of Cytology \& Tissue Biology

Journal of Dentistry: Oral Health \& Cosmesis

Journal of Diabetes \& Metabolic Disorders

Journal of Dairy Research \& Technology

Journal of Emergency Medicine Trauma \& Surgical Care

Journal of Environmental Science: Current Research

Journal of Food Science \& Nutrition

Journal of Forensic, Legal \& Investigative Sciences

Journal of Gastroenterology \& Hepatology Research

Journal of Gerontology \& Geriatric Medicine
Journal of Genetics \& Genomic Sciences

Journal of Hematology, Blood Transfusion \& Disorders

Journal of Human Endocrinology

Journal of Hospice \& Palliative Medical Care

Journal of Internal Medicine \& Primary Healthcare

Journal of Infectious \& Non Infectious Diseases

Journal of Light \& Laser: Current Trends

Journal of Modern Chemical Sciences

Journal of Medicine: Study \& Research

Journal of Nanotechnology: Nanomedicine \& Nanobiotechnology

Journal of Neonatology \& Clinical Pediatrics

Journal of Nephrology \& Renal Therapy

Journal of Non Invasive Vascular Investigation

Journal of Nuclear Medicine, Radiology \& Radiation Therapy

Journal of Obesity \& Weight Loss

Journal of Orthopedic Research \& Physiotherapy

Journal of Otolaryngology, Head \& Neck Surgery

Journal of Protein Research \& Bioinformatics

Journal of Pathology Clinical \& Medical Research

Journal of Pharmacology, Pharmaceutics \& Pharmacovigilance

Journal of Physical Medicine, Rehabilitation \& Disabilities

Journal of Plant Science: Current Research

Journal of Psychiatry, Depression \& Anxiety

Journal of Pulmonary Medicine \& Respiratory Research

Journal of Practical \& Professional Nursing

Journal of Reproductive Medicine, Gynaecology \& Obstetrics

Journal of Stem Cells Research, Development \& Therapy

Journal of Surgery: Current Trends \& Innovations

Journal of Toxicology: Current Research

Journal of Translational Science and Research

Trends in Anatomy \& Physiology

Journal of Vaccines Research \& Vaccination

Journal of Virology \& Antivirals

Archives of Surgery and Surgical Education

Sports Medicine and Injury Care Journal

International Journal of Case Reports and Therapeutic Studies

Journal of Ecology Research and Conservation Biology

Submit Your Manuscript: http://www.heraldopenaccess.us/Online-Submission.php 